\title{
Release of Interleukin 1 Inhibitory Activity (Contra-IL-1) by Human Monocyte-derived Macrophages Infected with Human Immunodeficiency Virus In Vitro and In Vivo
}

Richard M. Locksley, Suzanne Crowe, Michael D. Sadick, Frederick P. Heinzel, Kenneth D. Gardner, Jr., Michael S. McGrath, and John Mills

Departments of Medicine, University of California San Francisco Medical Center, San Francisco, California 94143; and the San Francisco General Hospital Medical Center, San Francisco, California 94110

\begin{abstract}
Infection of monocyte-macrophages with human immunodeficiency virus may be central to the pathogenesis of the acquired immunodeficiency syndrome. The ability of infected macrophages to prime $T$ cells through IL-1 production was investigated in vitro. Purified human monocytes maintained in suspension culture were infected with strain HIV-DV. Intracellular expression of virus p24 antigen increased from undetectable levels immediately after infection to 13-59\% of cells by 10-14 d; infected macrophages remained viable for up to $60 \mathrm{~d}$. Supernatants collected between 14 and $20 \mathrm{~d}$ after infection were examined in the murine thymocyte co-mitogenesis assay and demonstrated to contain a potent IL-1 inhibitor, designated contra-IL-1. Contra-IL-1 activity was present in all supernatants examined after $4 \mathrm{~d}$ of infection, and peaked coincident with peak p24 antigen expression. Inhibitory activity was not present in uninfected cells. Contra-IL-1 activity eluted after gel filtration with an approximate molecular weight of $9 \mathrm{kD}$. Inhibitory activity was removed by exposure to heat or acid $\mathrm{pH}$, or by incubation with chymotrypsin or staphylococcal V8 protease. Contra-IL-1 did not inhibit IL-2- or IL-4-dependent proliferation of murine $\mathbf{T}$ cell lines. Despite its ability to inhibit IL-1 activity, contra-IL-1 did not interfere with the binding of recombinant IL-1 $\beta$ to a fibroblast cell line. Contra-IL-1 inhibited the proliferation of normal peripheral blood mononuclear cells to both concanavalin $A$ and tetanus toxoid; inhibition could be attenuated by the addition of exogenous IL-1. Messenger RNA extracted from infected macrophages was examined by Northern analysis for the presence of message to IL-1 $\beta$. No message was apparent, suggesting that the presence of contra-IL-1 was not obscuring the concomitant release of
\end{abstract}

Presented in preliminary form at the 27th Interscience Conference on Antimicrobial Agents and Chemotherapy, 3-7 October 1987, New York, NY.

Address reprint requests to Dr. Locksley, Box 0654, Room C443, University of California at San Francisco Medical Center, San Francisco, CA 94143.

Received for publication 30 October 1987 and in revised form 20 June 1988.

1. Abbreviations used in this paper: TCID, tissue culture infective dose.

J. Clin. Invest.

(C) The American Society for Clinical Investigation, Inc. $0021-9738 / 88 / 12 / 2097 / 09 \$ 2.00$

Volume 82, December 1988, 2097-2105
IL-1. Infected macrophages stimulated with endotoxin generated readily detectable message for IL-1 $\beta$. Spleen macrophages purified from two patients with AIDS complicated by immune thrombocytopenia spontaneously expressed p24 antigen in vitro and released contra-IL-1 activity into the media. Contra-IL-1 may contribute to the immune dysfunction of AIDS.

\section{Introduction}

The mechanism by which HIV-1 produce immunodeficiency is not known. Although these viruses selectively infect and kill helper-inducer (CD4+) lymphocytes, depletion of CD4+ T cells does not completely reproduce the immune dysfunction that characterizes AIDS. The macrophage is also centrally involved in the generation of immune responses; recent reports documenting that HIV can productively infect this cell suggest that infection of macrophages may contribute to the pathogenesis of AIDS.

Since the initial description of the capacity for HIV to infect the human monocytic leukemia cell line, U937 (1), several investigators have shown that HIV-infected macrophages are present in brain (2-5) and lung (6) from infected patients. Human monocyte-derived macrophages support the replication of HIV (2, 7-9), and virus has been recovered from the monocyte fraction isolated from peripheral blood of AIDS patients (7). Macrophages are relatively resistant to syncytia formation and the cytopathic effects of HIV, presumably related to their lower density of surface CD4 molecules. Chronically infected macrophages may serve as a reservoir for virus in vivo that transmits infection to other susceptible cells. Additionally, infection of macrophages may underlie some of the defects in accessory cell function described in these patients (reviewed in 10, 11). Although incompletely characterized, such defects could be due to interference with ligand-receptor interactions required for cell-cell interaction, to an inability to release critical immunoregulatory cytokines such as IL-1, or to the release of molecules that inhibit these processes (12). We document here the release of IL-1 inhibitory activity, termed contra-IL-1 (13), from normal human monocyte-derived macrophages infected with HIV in vitro. Contra-IL-1 inhibited the proliferation of normal peripheral blood mononuclear cells to both mitogen and antigen, and this inhibition could be reversed by the addition of exogenous IL-1. Further, adherent mononuclear cells recovered from the spleen of patients with HIV infection constitutively released contra-IL-1, suggesting that infection in vivo is associated with production of this inhibitory activity. 


\section{Methods}

Monocyte-derived macrophages. Buffy coats from HIV-seronegative human donors were purchased from the Stanford Blood Bank (Palo Alto, CA) and the monocytes were isolated and maintained in suspension cultures as previously described (9). Briefly, the mononuclear cells were collected after separation over Ficoll-Hypaque (Pharmacia Fine Chemicals, Piscataway, NJ), washed, suspended in RPMI 1640 (Gibco Laboratories, Grand Island, NY) supplemented with $20 \%$ heat-inactivated FBS (Sterile Systems, Inc., Logan, UT), and allowed to adhere to sterile $150-\mathrm{mm}$ glass dishes for $1 \mathrm{~h}$ at $37^{\circ} \mathrm{C}$ in humidified $5 \% \mathrm{CO}_{2}$-air. Monolayers were washed vigorously with warm phosphate buffered, $\mathrm{Ca}^{2+}, \mathrm{Mg}^{2+}$-free saline, pH 7.2 (PBS), to remove nonadherent cells, covered with PBS containing 5\% FBS plus $0.2 \%$ EDTA, placed on ice, and scraped to recover the adherent cell population. After washing, cells were suspended in RPMI containing 10\% HIV-seronegative, heat-inactivated human AB serum (Stanford Blood Bank), $2 \mathrm{mM}$ Lglutamine and $50 \mu \mathrm{g} / \mathrm{ml}$ gentamicin, and distributed to polytetrafluorethylene (Teflon; Savillex Corp., Minneapolis, MN) jars at a concentration of $2 \times 10^{6}$ cells $/ \mathrm{ml}$. Media were changed weekly.

Spleen-derived macrophages. Splenic tissue was obtained in the operating room in accordance with institutional protocol following removal of the spleen from two patients with HIV infection complicated by immune thrombocytopenic purpura. After repeated massaging in cold RPMI to remove large amounts of blood, tissue was minced in cold RPMI, dispersed through a No. 100 sterile steel screen, and the cells collected by centrifugation. The mononuclear cells were collected following separation over Ficoll-Hypaque, and the macrophages were isolated by adherence, scraping, and distribution to Teflon jars as described above.

Virus. HIV-DV (kindly provided by G. Reyes, Gene Labs, Redwood City, CA), isolated from peripheral blood mononuclear cells of an AIDS patient with Kaposi's sarcoma, was used as a stock suspension prepared from the cell-free supernatant after growth in the CD4+ T cell lymphoma line, VB (kindly provided by J. Lifson, Gene Labs). The viral stock contained $10^{5.5} 50 \%$ tissue culture infective doses (TCID50) ${ }^{1}$ using the VB cytopathology assay (14), had $97,250 \mathrm{cpm} / \mathrm{ml}$ reverse transcriptase activity (15), and had an HIV p24 antigen concentration of $7.2 \mathrm{ng} / \mu \mathrm{l}(16)$. The viral stock was stored in small volumes at $-70^{\circ} \mathrm{C}$, and thawed immediately before use. Inactivated HIV-DV was prepared by heating samples to $100^{\circ} \mathrm{C}$ for $1 \mathrm{~h}$ before use.

Infection of mononuclear cells with HIV. Mononuclear cells were collected from the Teflon jars after 3-5 $\mathrm{d}$ in culture, washed and pretreated with $2 \mu \mathrm{g} / \mathrm{ml}$ hexadimethrine bromide (Polybrene; Sigma Chemical Co., St. Louis, MO) for $30 \mathrm{~min}$ before incubation in polypropylene tubes with viral stock at a multiplicity of infection of $\sim 1.0$ as described (9). Control cells from the same donors were incubated with media alone. After $2 \mathrm{~h}$ at $37^{\circ} \mathrm{C}$, the cells were washed twice, resuspended at $5 \times 10^{6}$ cells $/ \mathrm{ml}$ in fresh culture media, and returned to Teflon jars. Infection was documented by weekly assays of cell samples for intracytoplasmic immunofluorescence to p24 antigen (9) using murine monoclonal anti-HIV p24 (kindly provided by J. Carlson, California State AIDS Reference Laboratory, University of California Davis, Davis, CA) and quantitated by flow cytometric analysis using cytofluorograf-2S (Ortho Diagnostics, Raritan, NJ) equipped with a biohazard containment flow cell. Reverse transcriptase activity and HIV p24 antigen concentration were also assayed in serially collected supernatants.

Assay for $I L-1$ and contra- $I L-1$. Supernatants were collected from paired uninfected and HIV-infected macrophages, cleared by centrifugation $(10,000 \mathrm{~g}$ for $30 \mathrm{~min})$, and maintained at $4^{\circ}$ or $-20^{\circ} \mathrm{C}$. IL-1 activity was measured using the murine thymocyte comitogenesis assay as described (17). Experimental supernatants were added to quadruplicate wells in 96-well flat-bottomed microtiter plates (Costar Data Packaging, Cambridge, MA) at four serial twofold dilutions beginning from a final concentration of $25 \%$. Duplicate wells were assayed in the presence of $5 \mathrm{U} / \mathrm{ml}$ recombinant ( $\mathrm{r}$ ) human IL-1 $\beta$ (Genzyme Corp., Boston, MA). A standard IL-1 activity curve was generated for each experiment using serial dilutions of rIL- $1 \beta$ and was used to quantitate IL- 1 activity in U/ml. Contra-IL-1 activity was expressed in inhibitory units per milliliter where 1 inhibitory unit was designated the reciprocal of the highest dilution that produced $50 \%$ inhibition of $5 \mathrm{U} / \mathrm{ml}$ rIL-1 $\beta$.

Gel filtration. Supernatants containing contra-IL-1 activity were applied in 5-ml vol to a Sephacryl S-200 (Pharmacia Fine Chemicals) column $(2.5 \times 90 \mathrm{~cm})$ that had been previously calibrated at $4^{\circ} \mathrm{C}$ using immunoglobulin $\mathrm{G}(160,000 \mathrm{~mol} \mathrm{wt})$, BSA $(56,000 \mathrm{~mol} \mathrm{wt})$, ovalbu$\min (45,000 \mathrm{~mol} \mathrm{wt})$, carbonic anhydrase $(29,000 \mathrm{~mol} \mathrm{wt})$, cytochrome $c(12,000 \mathrm{~mol} \mathrm{wt})$, and aprotinin $(6,000 \mathrm{~mol} \mathrm{wt})$. Fractions were collected in 2-ml vol in PBS, $\mathrm{pH} \mathrm{7.2,} \mathrm{using} \mathrm{a} \mathrm{flow} \mathrm{rate} \mathrm{of} 2 \mathrm{ml} / \mathrm{h}$, passed through a $0.22-\mu \mathrm{m}$ filter, and assayed for contra-IL-1 activity at a final concentration of $10 \%$.

Biochemical characterization of contra-IL-1. In designated experiments, supernatants that contained contra-IL-1 activity were pretreated with heat $\left(56^{\circ} \mathrm{C} \times 30 \mathrm{~min}\right)$ or acid $\mathrm{pH}$ (adjusted to $\mathrm{pH} 2.2$ for 10 min with $1 \mathrm{~N} \mathrm{HCl}$ before neutralization) before being assayed for residual activity. Supernatants were also absorbed at $4^{\circ} \mathrm{C}$ by tumbling overnight with $10^{7}$ freshly harvested murine thymocytes or CTLL cells in a volume of $1 \mathrm{ml}$. Supernatants were collected by centrifugation $(10,000 \mathrm{~g}$ for $2 \mathrm{~min})$ and assayed for residual contra-IL-1 activity. Fractions separated by gel filtration that contained contra-IL-1 activity were tumbled at $37^{\circ} \mathrm{C}$ for $2 \mathrm{~h}$ with either chymotrypsin or staphylococcal V8 protease that had been linked to agarose beads; trypsin-chymotrypsin inhibitor (both from Sigma Chemical Co.) was added in excess either at the beginning or end of the incubation with chymotrypsin. The enzyme beads were removed by centrifugation and the residual contra-IL-1 activity was measured in the supernatants.

Assay for T cell growth factors. IL-2 was assayed using the IL-2-dependent murine cytotoxic T cell line CTLL as described (18). Briefly, 5 $\times 10^{3}$ washed cells in complete Click's media were distributed to quadruplicate microtiter wells containing $10 \mathrm{U} / \mathrm{ml}$ purified human IL- 2 in the presence or absence of serial dilutions of experimental supernatants beginning from a final concentration of $25 \%$. A standard IL-2 activity curve was generated using purified human IL-2. After incubation at $37^{\circ} \mathrm{C}$ for $20 \mathrm{~h}$, the wells were pulsed with $0.5 \mu \mathrm{Ci}\left[{ }^{3} \mathrm{H}\right]$ thymidine for $4 \mathrm{~h}$ before harvesting and measuring $\left[{ }^{3} \mathrm{H}\right]$ thymidine incorporation in a liquid scintillation counter.

The effect of gel-purified contra-IL-1 on IL-2 and IL-4 mediated proliferation was assessed using the murine HT-2 cell line (19) (kindly provided by Drs. R. L. Coffman and T. R. Mosmann, DNAX Research Institute, Palo Alto, CA) as described (20). In brief, quadruplicate wells in a 96-well microtiter tray containing $3 \times 10^{4}$ HT-2 cells/ well were assayed in the presence of either $5 \mu \mathrm{g} / \mathrm{ml}$ monoclonal antimurine IL-2, antimurine IL-4, or both. These neutralizing, rat antimurine IgG 1 monoclonal antibodies were partially purified by ammonium sulfate precipitation from ascites produced by the S4B6 anti-IL-2 (21) and the 11B11 anti-IL-4 (22) hybridoma cell lines (kindly supplied by Dr. T. R. Mosmann). Samples were assayed at a final concentration of $10 \%$ either in the presence of increasing concentrations of murine concanavalin A-stimulated spleen cell supernatants as a source of IL-2 or recombinant murine IL-4 (Genzyme Corp.). After incubation at $37^{\circ} \mathrm{C}$ in $5 \% \mathrm{CO}_{2}$-air for $24 \mathrm{~h}$, the numbers of surviving and/or proliferating cells were quantitated by colorimetric reduction of 3-(4,5-dimethylthiazol-2-yl)-2,5-diphenyl-tetrazolium bromide (MTT, $50 \mu \mathrm{g} /$ well; Sigma) as measured at $560 \mathrm{~nm}$ using a microelisa plate reader (Bio-Tek Instruments, Inc., Winooski, VT), as described (23).

$I L-1$ binding studies. Binding of ${ }^{125} \mathrm{I}$-labelled recombinant IL- $1 \beta$ (sp ac 3,000 Ci/mmol; DuPont New England Nuclear, Boston, MA) was assayed using the NIH BALB/3T3 murine fibroblast cell line as described (24). In brief, $5 \times 10^{6} 3 \mathrm{~T} 3$ cells in RPMI containing $1 \% \mathrm{BSA}$ and $0.2 \%$ sodium azide were tumbled in a volume of $1 \mathrm{ml}$ in duplicate Eppendorf tubes at $4^{\circ} \mathrm{C}$ in the presence of $20 \mathrm{ng} / \mathrm{ml}{ }^{125} \mathrm{I}-\mathrm{IL}-1$ in the presence or absence of gel-separated fractions that contained contraIL-1 activity. Designated tubes had $2 \mu \mathrm{g} / \mathrm{ml}$ cold recombinant IL- $1 \beta$ added at the start of the incubation. After varying periods of time, 
$100-\mu \mathrm{l}$ aliquots were transferred to precooled tubes containing a mixture of phthalate oils (1.5 parts dibutylphthalate and 1 part bis(-2-ethylhexyl)-phthalate (Eastman Kodak Co., Rochester, NY). The tubes were centrifuged $(10,000 \mathrm{~g}$ for $10 \mathrm{~min})$ and the tips containing the cell pellets excised and counted in a gamma counter (Gamma 5500; Beckman Instruments, Irvine, CA).

Proliferation of $P B M C$. Venous blood from normal HIV-seronegative volunteers was collected in heparin and the mononuclear cells isolated after centrifugation over Ficoll-Hypaque. After washing and hypotonic lysis of remaining erythrocytes, $4 \times 10^{5}$ PBMC were distributed to quadruplicate wells in 96-well microtiter plates containing serial dilutions of experimental supernatants. Wells were pulsed with either $1 \mu \mathrm{g} / \mathrm{ml}$ concanavalin A (Sigma), $5 \mu \mathrm{l}$ tetanus toxoid (Wyeth Laboratories, Marietta, PA), or media alone and incubated at $37^{\circ} \mathrm{C}$ in $5 \% \mathrm{CO}_{2}$-air. After 48 (Con A) or 96 (tetanus toxoid) h, wells were pulsed with $0.5 \mu \mathrm{Ci}\left[{ }^{3} \mathrm{H}\right]$ thymidine, and, after $18 \mathrm{~h}$ further incubation, collected using a cell harvestor (M. A. Bioproducts, Walkersville, MD) and counted in a liquid scintillation counter.

Analysis of macrophage $m R N A$. HIV-infected and uninfected macrophages $\left(5 \times 10^{6}\right.$ cells) were twice washed in $0.3 \mathrm{M} \mathrm{NaCl} / 0.03 \mathrm{M}$ sodium citrate buffer, $\mathrm{pH} 7$ (SSC) before extraction of total mRNA after lysis in guanidine $\mathrm{HCl}$ as described (25). HIV-infected and uninfected macrophages that had been incubated with $1 \mu \mathrm{g} / \mathrm{ml}$ Escherichia coli LPS (Sigma) for $8 \mathrm{~h}$ were also examined. After electrophoresis ( 50 $\mu \mathrm{g}$ mRNA per sample) in $6 \%$ formaldehyde/1\% agarose gel (26), samples were transferred to nylon membranes (27). Membranes were baked $\left(80^{\circ} \mathrm{C} \times 2 \mathrm{~h}\right)$ and treated for $4 \mathrm{~h}$ at $42^{\circ} \mathrm{C}$ in prehybridization solution ( $50 \%$ formamide, $0.02 \%$ Ficoll, $0.02 \%$ polyvinylpyrrolidone, $0.02 \%$ BSA, $1.5 \mathrm{M} \mathrm{NaCl}, 25 \mathrm{mM}$ phosphate buffer, $\mathrm{pH} 7.4$, and 200 $\mu \mathrm{M}$ denatured salmon sperm DNA) before incubation in prehybridization solution containing $50 \%$ dextran and a synthetic 40 -mer antisense oligonucleotide probe corresponding to residues 207-219 of the human IL- $1 \beta$ cDNA (28) that had been terminally labeled with [gamma- ${ }^{32}$ P]ATP (sp ac $3,000 \mathrm{mCi} / \mathrm{mol}$; New England Nuclear) using T4 polynucleotide kinase (International Biotechnology, Inc.; New Haven, CT) to a sp ac of $2 \times 10^{8} \mathrm{cpm} / \mu \mathrm{g}$ (26). After $24 \mathrm{~h}$ membranes were washed in $0.1 \%$ SDS $/ 2 \times$ SSC followed by $0.1 \%$ SDS/0.1X SSC before exposure to XAR-5 film (Eastman Kodak Co., Rochester, NY) at $-70^{\circ} \mathrm{C}$

Biohazard containment. Preparation of virus stocks, infection of macrophages with HIV, separation of macrophages from HIV-infected splenic tissues, and all cultures and assays involving infected cells were performed in a dedicated P2 $^{*}$ biohazard tissue culture containment facility in accordance with U. S. Public Health Service guidelines.

\section{Results}

Cells placed into suspension cultures after purification by $\mathrm{Fi}$ coll-Hypaque separation and glass adherence were 85-90\% monocytes/macrophages as assessed by nonspecific esterase staining, phagocytosis of yeast, and indirect immunofluorescence for Leu M3. After incubation with HIV (multiplicity of infection, 1:1), macrophages could be readily infected in suspension cultures, as determined both by intracellular p24 antigen expression as assessed by flow cytometry, and by reverse transcriptase activity measured in the culture supernatants (9). Contaminating $\mathrm{T}$ lymphocytes comprised $\sim 3 \%$ of initial suspension cultures (CD3+ immunofluorescence by flow cytometric analysis), but completely disappeared within $14 \mathrm{~d}$ of addition of HIV; macrophages remained viable for up to 60 days in vitro (9).

Supernatants were collected from 14 to $20 \mathrm{~d}$ after infection of macrophages with HIV from five different donors that expressed p24 antigen in 13 to $59 \%$ of cells. None displayed activity in the murine thymocyte assay for IL-1. In contrast, each contained activity that blocked the capacity of the thy-

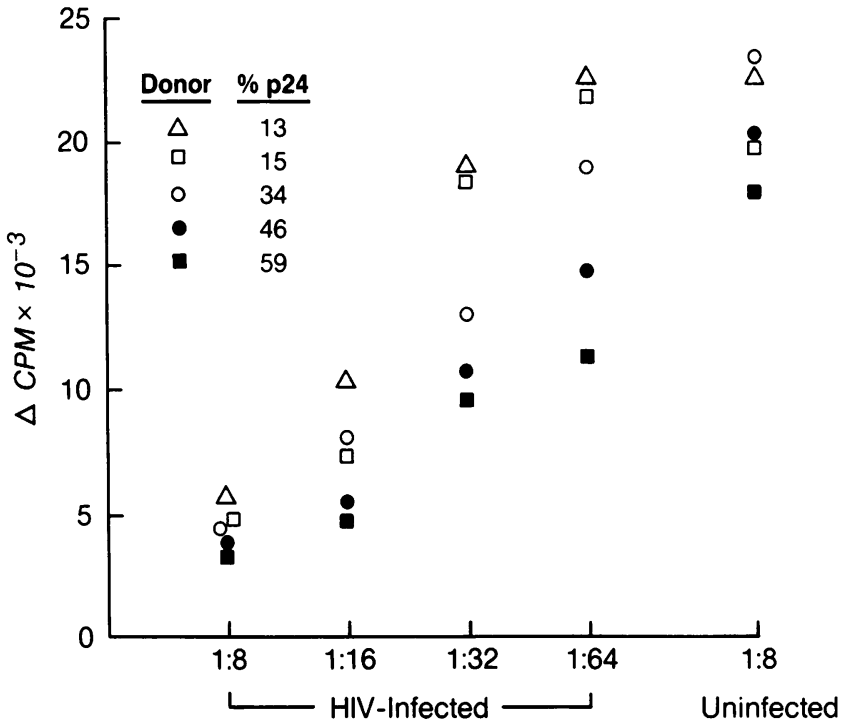

Figure 1. Production of IL-1 inhibitory activity by HIV-infected macrophages. Supernatants were collected between 14 and $20 \mathrm{~d}$ after infection of macrophages from five donors with HIV and tested for their ability to interfere with the proliferation of murine thymocytes to $5 \mathrm{U} / \mathrm{ml} \mathrm{rIL-} 1 \beta$ as assessed by $\left[{ }^{3} \mathrm{H}\right]$ thymidine incorporation above unstimulated levels. Supernatants from HIV-infected and matched, uninfected macrophages were assayed at the dilutions designated. Each point represents the mean of quadruplicate samples with variation of $<10 \%$ between replicates. Thymocytes in the absence of rIL-1 $\beta$ took up $1,200 \pm 700 \mathrm{cpm}$. (Inset) The percentage of each donor's macrophages that expressed p24 antigen as assessed by immunofluorescence and flow cytometry at the time the supernatants were assayed for contra-IL-1.

mocytes to respond to exogenous rIL-1 $\beta$ (Fig. 1). Supernatants were not directly toxic to the thymocytes as assessed by trypan blue exclusion. This blocking activity, termed contra-IL-1 (13), could be detected in supernatants diluted 16- to 64-fold. By using the reciprocal inhibitory dilution to quantitate units of contra-IL-1 activity (see Methods), it was possible to demonstrate a correlation between $\mathrm{p} 24$ expression and contra-IL-1 activity (Fig. 1). No thymocyte inhibitory activity was present in the supernatants from the uninfected macrophages from the same donors. Measurable contra-IL-1 activity required replication of HIV within macrophages, since supernatants from uninfected macrophages, supernatants from macrophages mock-infected with heat-killed HIV, and supernatants from CD4+ VB cells heavily infected with replicating HIV all lacked inhibitory activity in the IL-1 assay (Table I). HIV itself did not inhibit murine thymocyte proliferation.

The kinetics of contra-IL-1 production were examined using macrophages from three separate donors; a representative experiment is shown (Fig. 2). At 3 and $5 \mathrm{~d}$ after infection with HIV, no IL-1 inhibitory activity could be demonstrated in the thymocyte assay. Contra-IL-1 could be measured at all later time points; activity peaked at $14 \mathrm{~d}$, at approximately the same time as peak p24 antigen expression. Comparable results were obtained with the two other donors' cells.

Although contra-IL-1 inhibited thymocyte proliferation to IL-1, it had no effects on the proliferation of the IL-2-dependent cell line CTLL to IL-2 (Table II). Overnight preincubation of contra-IL-1-containing supernatants with thymocytes 
Table I. Effects of HIV-infected Cell Supernatants on Thymocyte Proliferation*

\begin{tabular}{cr}
\hline & \multicolumn{1}{c}{$\Delta$ cpm $^{\ddagger}$} \\
\hline Thymocytes + PHA + rIL-1 (8) & $19,700 \pm 3,090$ \\
+ HIV-infected macrophages (8) & $4,200 \pm 1,150$ \\
+ Uninfected macrophages (8) & $23,150 \pm 3,180$ \\
+ Mock-infected macrophages (2) & $24,150 \pm 4,810$ \\
+ HIV-infected VB cells (3) & $20,020 \pm 3,340$ \\
+ HIV (3) & $17,980 \pm 1,900$ \\
\hline
\end{tabular}

* $10^{6}$ thymocytes, $1 \mu \mathrm{g} / \mathrm{ml}$ PHA, and $5 \mathrm{U} / \mathrm{ml}$ rIL- $1 \beta$ were incubated in quadruplicate microtiter wells alone or with a 1:8 dilution of the supernatants designated. Number of experiments denoted in parentheses. Supernatants were collected between 14 and $20 \mathrm{~d}$ from macrophages that had been inoculated with either HIV or heat-inactivated HIV (mock-infected) on day 1, or from donor-matched uninfected controls. Supernatants from HIV-infected VB cells were collected at the time of maximum giant cell formation and either used directly or after filtration $(0.22 \mu \mathrm{m})$ to remove cellular material. ‡ Wells were pulsed with $\left[{ }^{3} \mathrm{H}\right]$ thymidine after $48 \mathrm{~h}$ and the incorporated radioactivity quantitated $18 \mathrm{~h}$ later. Results are expressed as mean \pm SEM after subtracting the uptake by thymocytes incubated with PHA in the absence of rlL- $1 \beta(1,700 \pm 500)$.

at $4^{\circ} \mathrm{C}$ significantly reduced activity, whereas preincubation with comparable numbers of CTLL cells did not. Contra-IL-1 was stable to freeze-thawing, but was inactivated by exposure to $\mathrm{pH} 2.2$ or $56^{\circ} \mathrm{C}$ for $30 \mathrm{~min}$. Activity was nondialyzable, and could be recovered in the precipitate after incubation with $50 \%$ ammonium sulfate (data not shown). Levels of $\mathrm{PGE}_{2}$ were comparable in supernatants from infected $(4-22 \mathrm{pg} / \mu \mathrm{l})$ and uninfected (13-34 pg/ $\mathrm{ll}$ ) macrophages as assessed by competitive RIA.

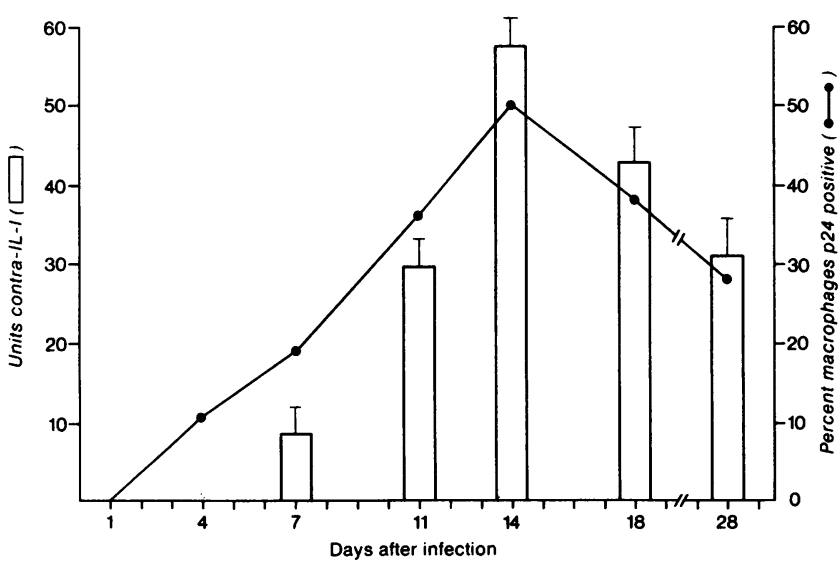

Figure 2. Kinetics of contra-IL-1 production and p24 expression. Macrophages in suspension were infected with HIV and maintained in culture for $25 \mathrm{~d}$ (see Methods). Supernatants were assayed on the days designated for their ability to inhibit the proliferation of murine thymocytes. Contra-IL-1 activity is expressed in units where $1 \mathrm{U}$ caused $50 \%$ inhibition of thymocytes to $5 \mathrm{U} / \mathrm{ml}$ rIL-1 $\beta$. Bars represent the mean of quadruplicate assays with SEM shown above. Aliquots of the cells were permeabilized and examined for viral p24 antigen expression using immunofluorescence. Uninfected macrophages from the same donor released no contra-IL-1 activity and were uniformly p24 antigen negative.
Table II. Characterization of Contra-IL-1*

\begin{tabular}{llr}
\hline \multicolumn{1}{c}{ Cells } & \multicolumn{1}{c}{ Addition } \\
\hline & & \multicolumn{1}{c}{$\Delta \mathrm{cpm}$} \\
CTLL & & $32,340 \pm 4,200$ \\
& IL-2 $(10 \mathrm{U} / \mathrm{ml})$ & $36,110 \pm 3,980$ \\
Thymocytes & IL-2 + 25 U contra-IL-1 & $14,800 \pm 3,050$ \\
& PHA + IL-1 (5 U/mil) & $3,780 \pm 1,100$ \\
& +25 U contra-IL-1 & $10,640 \pm 2,250$ \\
& Thymocyte preabsorption ${ }^{\ddagger}$ & $4,410 \pm 1,800$ \\
& CTLL preabsorption & $12,250 \pm 2,600$ \\
& pH $2.2 \times 10$ min & $10,400 \pm 2,100$
\end{tabular}

* Supernatant collected from HIV-infected macrophages was added to either CTLL or thymocyte proliferation assays and $\left[{ }^{3} \mathrm{H}\right]$ thymidine incorporation quantitated as described (Methods).

‡ Supernatant containing contra-IL- 1 was tumbled overnight at $4^{\circ} \mathrm{C}$ with either $10^{7}$ CTLL or $10^{7}$ thymocytes in a volume of $1 \mathrm{ml}$. Supernatants were collected after centrifugation $(10,000 \mathrm{~g} \times 2 \mathrm{~min})$ and used in the proliferative assay.

Supernatants containing contra-IL-1 activity were separated by gel filtration over Sephacryl S-200 and the collected fractions assayed for inhibitory activity in the presence of 5 $\mathrm{U} / \mathrm{ml} \mathrm{rIL-1} \beta$ (Fig. 3). Inhibitory activity eluted as a relatively sharp peak with an approximate molecular weight of $9 \mathrm{kD}$. No IL- 1 activity could be demonstrated when the same fractions were assayed in the absence of rIL-1 for endogenous thymocyte comitogenic activity (data not shown).

The capacity of the gel purified fractions containing contra-IL-1 activity to interfere with $T$ cell proliferation was assessed using the murine HT-2 T cell line that divides only in the presence of either of the T cell growth factors IL-2 or IL-4 (20). By using a neutralizing monoclonal antibody to IL-2, it

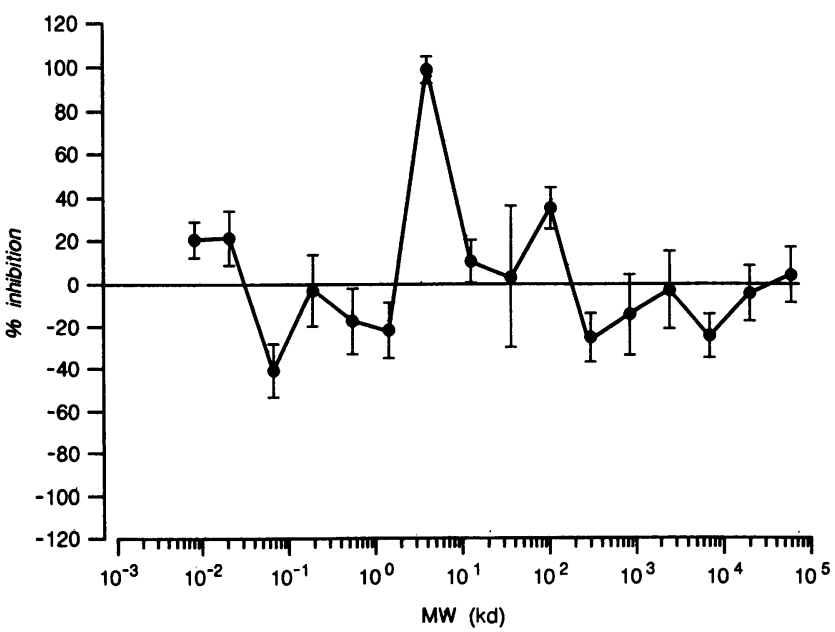

Figure 3. Gel separation of contra-IL-1 containing supernatants. Supernatant from HIV-infected macrophages was separated over a Sephacryl S-200 column and the elution fractions assayed in the thymocyte co-mitogenesis assay in the presence of rIL-1 $\beta$. 
A

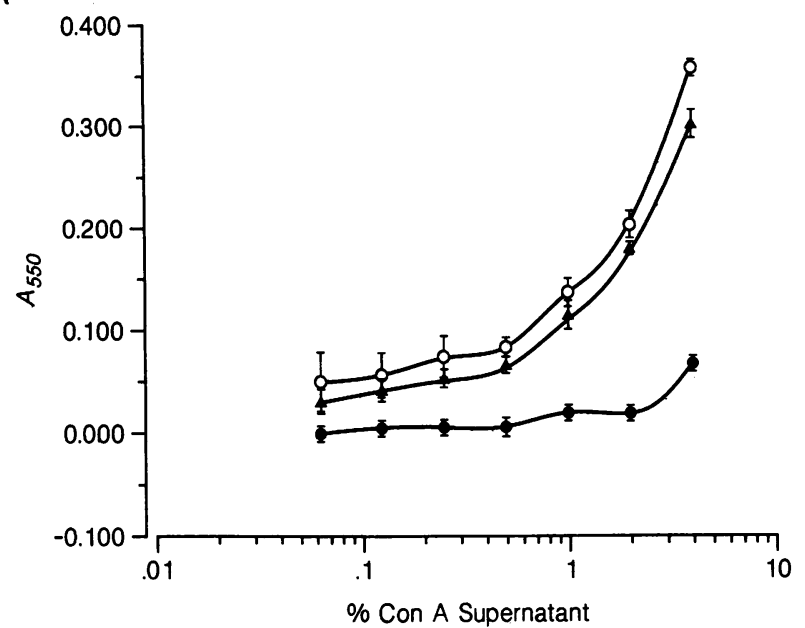

B

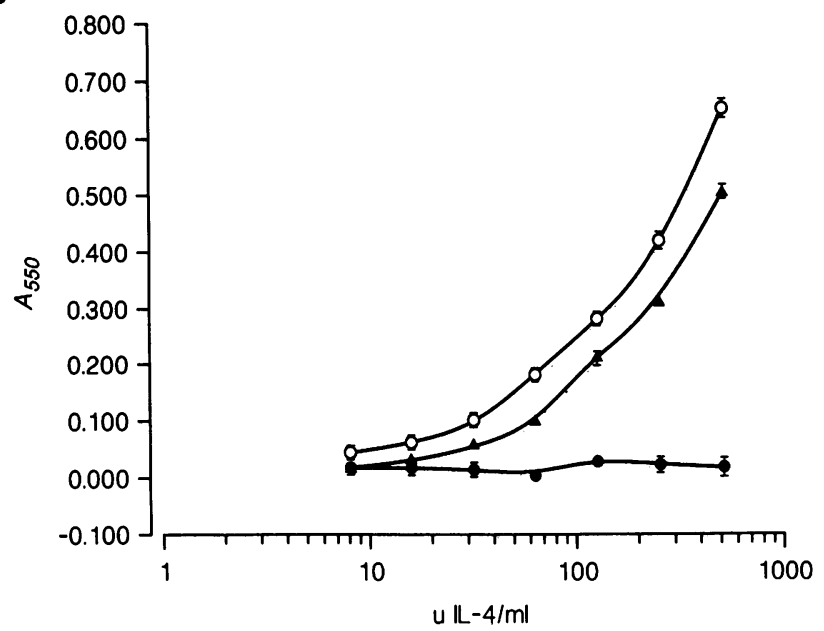

Figure 4. Effects of contra-IL-1 on IL-2- and IL-4- mediated HT2 proliferation. $(A)$ Proliferation of HT2 cells to increasing concentrations of concanavalin A-stimulated spleen cell supernatants in the presence $(-\bullet-)$ ) or absence $(-0-)$ of monoclonal anti-IL-2 antibody, and in the presence of $10 \%$ gel-purified contra-IL-1 (- -$)$. $(B)$ Proliferation of HT2 cells to increasing concentrations of recombinant IL-4 in the presence $(-\bullet-)$ or absence $(-\circ-)$ of monoclonal anti-IL- 4 antibody, and in the presence of $10 \%$ gel-purified contra-IL-1 (- $\Delta-)$.

was possible to show that the major $\mathrm{T}$ cell growth factor in concanavalin A-stimulated murine spleen cell supernatants was IL-2 (Fig. $4 A$ ). Further, a concentration of contra-IL-1 that inhibited thymocyte proliferation by over $75 \%$ had no effect on HT-2 cells throughout the ascending portion of the dose response curve to the spleen cell supernatants. A similar growth curve of HT-2 cells was demonstrated in response to recombinant murine IL-4 (Fig. $4 \mathrm{~B}$ ). Contra-IL-1 containing fractions produce a small shift in the dose response curve of HT-2 cells to IL-4, although this was not consistently seen. Peak proliferation of HT-2 cells to either IL-2 or IL-4 was unaffected by contra-IL-1 fractions (data not shown).

The gel-purified fractions containing contra-IL-1 activity were used to assess the sensitivity of contra-IL-1 to protease digestion. For these experiments, samples containing contraIL-1 were tumbled for $2 \mathrm{~h}$ at $37^{\circ} \mathrm{C}$ with either chymotrypsin or
Table III. Sensitivity of Contra-IL-1 to Protease Digestion*

\begin{tabular}{cc}
\hline \multicolumn{2}{c}{ Sample } \\
\hline & $\Delta \mathrm{cpm}^{*}$ \\
Thymocytes + 2 U/ml rIL-1 $\beta$ & $9,200 \pm 300$ \\
$+5 \%$ contra-IL-1 & $4,050 \pm 220$ \\
+ Staph V8 protease & $9,120 \pm 250$ \\
+ Chymotrypsin & $9,050 \pm 200$ \\
+ Chymotrypsin inhibitor & $4,350 \pm 350$ \\
+ Chymotrypsin/chymotrypsin & \\
inhibitor & $4,980 \pm 220$ \\
\hline
\end{tabular}

* Gel-purified fractions containing contra-IL-1 activity were incubated in triplicate samples at $37^{\circ} \mathrm{C}$ for $2 \mathrm{~h}$ either alone or in the presence of the designated agarose-linked proteases or inhibitor. The enzyme-linked beads were cleared by centrifugation and the supernatants assayed for residual IL-1 inhibitory activity using thymocytes stimulated in the presence of $1 \mu \mathrm{g} / \mathrm{ml}$ PHA and $2 \mathrm{U} / \mathrm{ml} \mathrm{rIL-} 1 \beta$. ${ }^{\ddagger}\left[{ }^{3} \mathrm{H}\right]$ Thymidine uptake expressed as mean \pm SEM after subtracting the uptake of thymocytes incubated with PHA alone $(1,200 \pm 450)$.

staphylococcal V8 protease that had been coupled to agarose beads, the beads were cleared by centrifugation, and the residual inhibitory activity assayed in the thymocyte assay. Both enzymes completely destroyed contra-IL-1 activity under these conditions, whereas fractions incubated at $37^{\circ} \mathrm{C}$ without proteases were completely active (Table III). Addition of chymotrypsin inhibitor in excess at the beginning (but not at the end) of the incubation with chymotrypsin resulted in protection of contra-IL-1 activity.

To investigate more carefully the possibility that IL-1 gene expression in HIV-infected macrophages was being masked by the production of contra-IL-1, we hybridized extracted mRNA with a specific human IL- $1 \beta$ probe (Fig. 5). No hybridization with the IL-1 probe could be demonstrated in infected macrophages, although a faint band of the appropriate size $(1.3 \mathrm{~kb})$ could be detected in the uninfected macrophages. The latter may reflect some activation due to aggregation or adherence occurring during preparation of the cells (29). Macrophages from four donors were infected for 10-14 $d$ and incubated with fresh media or $1 \mu \mathrm{g} / \mathrm{ml}$ LPS for $8 \mathrm{~h}$ before extraction of
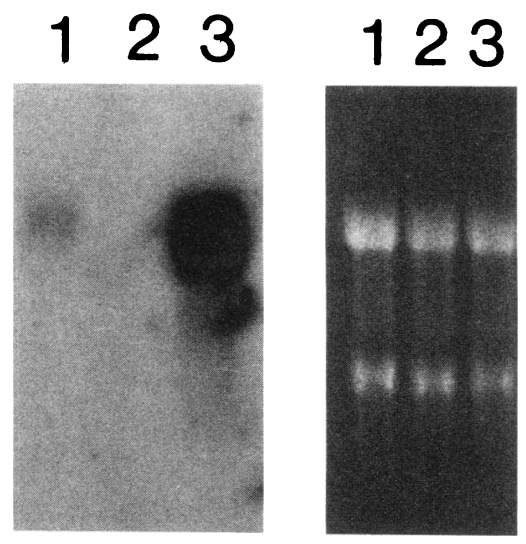

Figure 5. IL-1 $\beta$ mRNA expression in macrophages. mRNA was extracted from uninfected (lane 1), HIV-infected (lane 2) or uninfected, LPS-stimulated (lane 3) macrophages from the same donor after $20 \mathrm{~d}$ culture in vitro, electrophoresed, transferred to nylon membranes and hybridized with a ${ }^{32} \mathrm{P}$ labeled oligonucleotide probe specific for IL- $1 \beta$ (left panel; see Methods). Ethidium bromide staining was used to confirm that comparable amounts of mRNA had been loaded for each sample (right panel). 


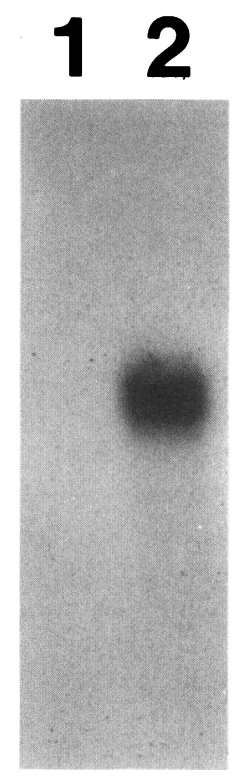

Figure 6. Endotoxin-mediated IL-1 $\beta$ mRNA expression in HIV-infected macrophages. mRNA was extracted from HIV-infected macrophages from four donors after $10-14 \mathrm{~d}$ culture in vitro following incubation with media alone (lane 1 ) or $1 \mu \mathrm{g} / \mathrm{ml} \mathrm{LPS} \mathrm{for} 8 \mathrm{~h}$ (lane 2), and hybridized to a ${ }^{32} \mathrm{P}$-labeled IL- $1 \beta$ oligonucleotide probe before autoradiography.

mRNA and hybridization with the IL- $1 \beta$ probe (Fig. 6). Again, no IL- $1 \beta$ mRNA was detected in the infected cells, although these cells readily generated IL-1 in response to LPS.

The capacity of contra-IL-1 to inhibit the proliferative response of normal peripheral blood mononuclear cells to concanavalin A and to tetanus toxoid was examined next (Table IV). In three donors, $50 \mathrm{U} / \mathrm{ml}$ contra-IL-1 inhibited the proliferative response to con $\mathrm{A}$ by $57-70 \%$, and to tetanus toxoid by $35-71 \%$. Inhibition was dose dependent, and the effect could be attenuated by the addition of exogeneous rIL- $1 \beta$. There was no direct cellular toxicity of contra-IL-1 as assessed by trypan blue exclusion.

Because of the ability of exogenous IL-1 to overcome partially the effects of contra-IL-1 on the proliferation of peripheral blood mononuclear cells, we next examined the capacity of gel separated fractions containing contra-IL-1 activity to inhibit the binding of rIL- $1 \beta$ to its receptor. These experiments used the murine 3T3 fibroblast cell line that has been shown to possess a relatively large number of IL-1 receptors similar to

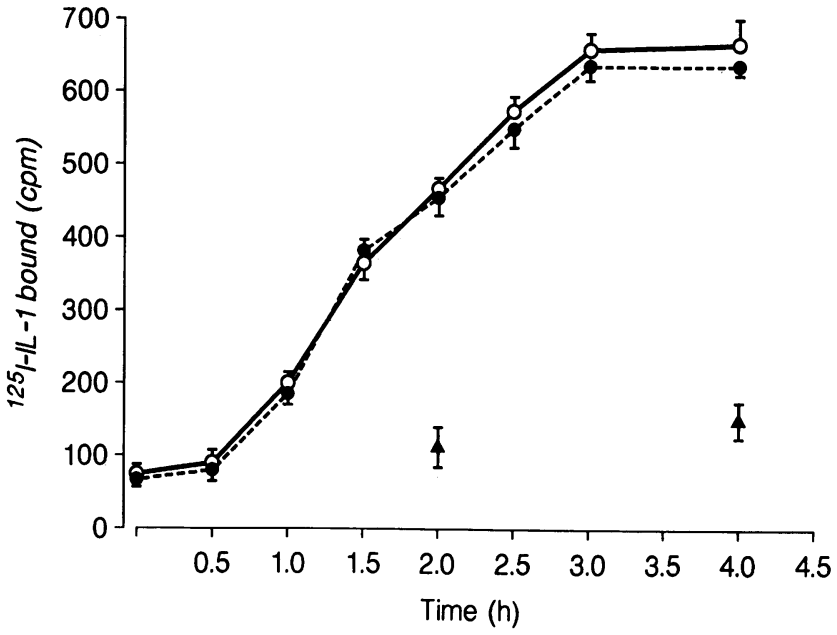

Figure 7. Binding of ${ }^{125}$ I-rIL-1 $\beta$ to $3 \mathrm{~T} 3$ cells. 3T3 cells were incubated at $4^{\circ} \mathrm{C}$ for the designated periods of time in the presence of ${ }^{125} \mathrm{I}$-rIL-1 $\beta$ in the presence $(\cdots \cdots)$ or absence $(-0-)$ of contra-IL-1 before centrifugation through phthalate oil and determination of cell-associated radioactivity. Cold rIL- $1 \beta$ was used in excess to assess specificity of the binding assay $(-\Delta-)$.

those on T cells that bind both human IL-1 $\beta$ and IL- $1 \alpha$ in a competitive manner (24). Equilibrium binding of ${ }^{125} \mathrm{IL}-1 \beta$ could be established by $3 \mathrm{~h}$ incubation at $4^{\circ} \mathrm{C}$ (Fig. 7). ContraIL-1 at concentrations that maximally inhibited thymocyte proliferation had no effects on ${ }^{125}$ IL-1 $\beta$ binding.

The HIV isolate used in these studies, HIV-DV, grows well in macrophages, particularly as compared with the prototypic HIV-IIIB strain that has been propagated in T cell lines $(2,9)$. To assess whether contra-IL-1 could be produced in vivo during HIV infection, adherent cells were established in culture from the spleens of two HIV-infected patients requiring splenectomy for thrombocytopenia. Immediately after isolation, 3 and 5\% (patients 1 and 2, respectively) of the adherent cells contained p 24 antigen as assessed by flow cytometry. At day 5 , 33 and $28 \%$ of the cells were positive for p24 and the media demonstrated soluble p24 antigen. Assay of media collected after day 7 yielded 36 and $46 \mathrm{IU} / \mathrm{ml}$ of contra-IL-1 activity (54\% and $72 \%$ inhibition of thymocyte proliferation to $5 \mathrm{U} / \mathrm{ml}$

Table IV. Contra-IL-1 Inhibits Proliferation of Peripheral Blood Mononuclear Cells to Mitogen and Antigen*

\begin{tabular}{|c|c|c|c|c|c|c|c|c|c|}
\hline \multirow[b]{2}{*}{ Donor } & & \multicolumn{4}{|c|}{ Concanavalin A } & \multicolumn{4}{|c|}{ Tetanus Toxoid } \\
\hline & & Control & $1: 8$ & $1: 16$ & $1: 32$ & Control & $1: 8$ & 1:16 & $1: 32$ \\
\hline \multirow[t]{2}{*}{1} & & $35,230^{\ddagger}$ & 11,110 & 15,200 & 26,840 & 26,210 & 17,100 & 19,700 & 26,400 \\
\hline & $+5 \mathrm{U} / \mathrm{ml}$ rIL-1 $\beta$ & - & 24,820 & 28,800 & 31,220 & - & 22,400 & 23,580 & 27,210 \\
\hline \multirow[t]{2}{*}{2} & & 27,890 & 8,430 & 11,900 & 19,600 & 21,400 & 6,200 & 9,800 & 16,400 \\
\hline & $+5 \mathrm{U} / \mathrm{ml}$ rIL- $1 \beta$ & - & 12,650 & 16,980 & 22,450 & - & 11,500 & 14,300 & 19,880 \\
\hline \multirow[t]{2}{*}{3} & & 47,420 & 20,200 & 28,280 & 39,250 & 18,900 & 9,800 & 12,400 & 15,500 \\
\hline & $+5 \mathrm{U} / \mathrm{ml} \mathrm{rIL-1} \beta$ & - & 25,100 & 35,750 & 49,400 & - & 12,200 & 15,800 & 17,200 \\
\hline
\end{tabular}

* Supernatant from HIV-infected macrophages that contained $50 \mathrm{U} / \mathrm{ml}$ contra-IL-1 activity was added at the dilutions designated to peripheral blood mononuclear cells from three donors and incubated with either $1 \mu \mathrm{g} / \mathrm{ml}$ concanavalin A or $5 \mu$ l tetanus toxoid in the absence or presence of $5 \mathrm{U}$ rIL-1 $\beta$. Proliferation was assessed by $\left[{ }^{3} \mathrm{H}\right]$ thymidine incorporation (see Methods). ${ }^{\ddagger}$ Represents $\Delta$ cpm of quadruplicate samples. SEM $\leqslant 12 \%$. Incorporation in the absence of mitogen or antigen was $4,100 \pm 2,100 \mathrm{cpm}$. Addition of IL-1 to control incubations with mitogen or antigen alone did not significantly enhance $\left[{ }^{3} \mathrm{H}\right]$ thymidine incorporation. 
rIL- $1 \beta$ at a dilution of $1: 32$ ), indicating that wild-type HIV can induce contra-IL-1 release from human macrophages.

\section{Discussion}

Infection of human monocyte-derived macrophages in suspension with HIV was associated with the production of a potent inhibitor of the thymocyte activating capacity of IL-1. The IL- 1 inhibitory activity eluted at an approximate molecular weight of 9,000 D after gel filtration, and was sensitive to heat, acid $\mathrm{pH}$ or protease digestion. Contra-IL-1 inhibited the proliferative responses of normal human peripheral blood mononuclear cells to both concanavalin A and tetanus toxoid in a dose-dependent manner. Although inhibition could be partially reversed by the addition of exogenous IL-1, contraIL-1 did not interfere with the binding of IL-1 to its receptor on 3 T3 cells. Contra-IL-1 had no effect on the IL-2- or IL-4dependent proliferation of $\mathrm{T}$ cell lines. Finally, cultures of adherent cells derived from the spleen of two AIDS patients were demonstrated to be infected with HIV and spontaneously released contra-IL-1 into the media following in vitro cultivation without the addition of exogenous virus.

The cell populations used in these studies consisted of 85-90\% macrophages as defined by several histologic and antigenic criteria, suggesting that these cells are the source of contra-IL-1 activity. Contaminating CD4+ T lymphocytes, another cell supporting the intracellular replication of HIV, never comprised more than $3 \%$ of the original cell population and were entirely absent after $7 \mathrm{~d}$ of culture. Recovery of contra-IL-1 peaked at the time of maximum macrophage p24 viral antigen expression, consistent with a role for viral replication in the stimulation of contra-IL-1 release. Viral infection of macrophages was required for contra-IL-1 production, since no activity was recovered after incubation of cells with nonviable virus and no activity was present in supernatants taken from infected VB T lymphoma cells. The last experiment suggests that under these conditions the inhibition of IL-1 was not due to a direct effect of retrovirus envelope protein (30).

Although IL-1 is a predominant macrophage cytokine, the molecule can be produced by a wide range of cells and has numerous activities that, in general, orchestrate the host response to pathogens $(31,32)$. Aside from its ability to activate lymphocytes, IL-1 also has been implicated in the genesis of fever, the hepatic acute phase protein synthetic response, muscle and fat catabolism, endothelial cell activation, bone remodelling, the degradation of extracellular matrix, the stress hormone response, and defense against tumors. It is not unexpected that an inhibitor of such a widely distributed, highly bioactive molecule would be found, and that it might be produced by those cells that make IL-1. Indeed, contra-IL-1 activity, first described in sera (33) and urine (34) from febrile patients, has been recovered from multiple cell types, including monocytes and macrophages (35-37), neutrophils (38), endothelial $(39,40)$ and epithelial cells $(41)$, as well as from EBV-transformed B cell lines (13) and the macrophage-like U937 cell line (42). Although the mechanisms underlying the regulatory control of contra-IL-1 release remain unknown, the reports that several viruses, including cytomegalovirus, EBV, influenza virus, and respiratory syncytial virus, may trigger the release of this activity from macrophages $(36,43)$, together with the data for HIV presented here, suggest that virus-macrophage interaction may be commonly involved. Although others have reported co-production of IL-1 by cells stimulated to release contra-IL-1 $(12,36)$, we were unable to demonstrate message for IL- $1 \beta$ in macrophages infected with HIV. Message for IL- $1 \beta$ is tenfold more abundant than that for IL- $1 \alpha$ in human monocytes (44) and control of IL-1 protein secretion is felt to be regulated largely at the transcriptional level (45). Message for IL- $1 \beta$ could be readily detected in both uninfected and infected LPS-stimulated cells, indicating that HIV-infected macrophages are capable of producing IL-1 when appropriately stimulated. Taken together, these data make it unlikely that IL-1 transcription was occurring in these HIV-infected cells. The inability to demonstrate IL-1 production may reflect the in vitro differentiation of the cells used for the mRNA extractions (10-20 d), since prolonged culture of macrophages has been demonstrated to attenuate the capacity to generate IL-1 (46).

The ability to absorb contra-IL-1 onto thymocytes, in agreement with previous reports (13), suggests that inhibition is occurring at the level of the thymocyte rather than via binding to soluble IL-1. We cannot rule out the possibility that contra IL-1 might have inhibitory effects on other thymocyte proliferative interleukins, including TNF- $\alpha$ (47) or IL-6 (48). The shift in the response curve of HT-2 cells to IL-4 in the presence of contra-IL-1, although small, might reflect interference with IL-1 effects (49). Low molecular weight inhibitors of IL-1, such as thymidine or PGE 2 , did not account for the inhibitory activity measured in these experiments. Uromodulin, which inactivates IL-1 through direct binding by carbohydrate side chains (50), also seems an unlikely candidate in view of its molecular weight $(85 \mathrm{kD})$ and reported production solely in the kidney; evidence suggests that uromodulin is identical to Tamm-Horsfall glycoprotein (51). The acid stability and IL-2 inhibitory activity of transforming growth factor- $\beta$, another potent inhibitor of mitogenesis, are distinct from those of contra-IL-1 (52). The approximate molecular weight of contraIL-1 reported here is in agreement with a previously described inhibitor, recovered from the supernatants of peripheral blood mononuclear cells from patients with AIDS and, in lower titer, from healthy individuals (12). We were unable to demonstrate competition by contra-IL-1 for IL-1 binding to its receptor on fibroblasts, suggesting that inhibition occurs at a postbinding site. Others have reported both inhibition of binding (53) and no inhibition (54) by IL-1 inhibitors of higher molecular weights isolated from urine from febrile patients. The biochemical and molecular characterization of this widely demonstrated biological activity awaits further study, but will be required in order to determine whether all of these activities are mediated by a single cytokine or a family of molecules.

The potential role of contra-IL-1 in the pathogenesis of AIDS remains unknown. Some of the accessory cell dysfunction described among patients' cells are consistent with the effects of contra-IL-1 demonstrated here, including diminished proliferation of peripheral blood mononuclear cells to mitogen and antigen. The potential for in vivo production of contra-IL-1 by HIV infected macrophages is supported by our data using cells isolated from the spleen of HIV-infected patients and from the results of Berman and colleagues using unfractionated peripheral blood cells from AIDS patients (12). Contra-IL-1 has also been isolated from synovial mononuclear phagocytes from patients with rheumatoid arthritis, and has been demonstrated to not only block lymphoproliferation, but also to inhibit T cell production of IL-2 and gamma-IFN (37). 
Diminished production of gamma-IFN has been reported from cells from AIDS patients and has been correlated with increased risk of opportunistic infection (55). Loss of gammaIFN production might contribute to the diminished class II MHC antigen expression that has been demonstrated in AIDS patients $(56,57)$; alternatively, this may reflect a direct effect of viral infection (58). Loss of class II MHC together with release of a soluble IL-1 inhibitor would be expected to profoundly impair the accessory cell function of infected macrophages. Efforts to purify contra-IL-1 are needed in order to fully examine the biological activity and regulatory control of this potentially important cytokine.

\section{Acknowledgments}

The authors gratefully acknowledge the technical assistance of Vicki Shigekane, Nancy McManus, and Jean Kirihara, and the secretarial support of Jim Walker.

Supported by BRSG RR-05355 and AI-25329 from the National Institutes of Health, the Universitywide Task Force on AIDS (M. McGrath and J. Mills) from the state of California, the MacArthur Foundation, and MSC 51 (Blair) Funds to the UCSF School of Medicine. S. Crowe is a recipient of a Harkness Fellowship.

\section{References}

1. Dalgleish, A. G., P. C. L. Beverley, P. R. Clapham, D. H. Crawford, M. F. Greaves, and R. A. Weiss. 1984. The CD4 (T4) antigen is an essential component of the receptor for the AIDS retrovirus. Nature (Lond.). 312:763-767.

2. Gartner, S., P. Markovits, D. M. Markovitz, M. H. Kaplan, R. C. Gallo, and M. Popovic. 1986. The role of mononuclear phagocytes in HTLV-III/LAV infection. Science (Wash. DC). 233:215-219.

3. Koenig, S., H. E. Gendelman, J. M. Orenstein, M. C. Dal Canto, G. H. Pezeshkpour, M. Yungbluth, F. Janotta, A. Aksamit, M. A. Martin, and A. S. Fauci. 1986. Detection of AIDS virus in macrophages in brain tissue from AIDS patients with encephalopathy. Science (Wash. DC). 233:1089-1093.

4. Gartner, S., P. Markovits, D. M. Markovitz, R. F. Betts, and M. Popovic. 1986. Virus isolation from and identification of HTLV-III/ LAV-producing cells in brain tissue from a patient with AIDS. $J A M A$ (J. Am. Med. Assoc.). 256:2365-2371.

5. Stoler, M. H., T. A. Eskin, S. Benn, R. C. Angerer, and L. M. Angerer. 1986. Human T-cell lymphotropic virus type III infection of the central nervous system. A preliminary in situ analysis. JAMA (J. Am. Med. Assoc.). 256:2360-2364.

6. Salahuddin, S. Z., R. M. Rose, J. E. Groopman, P. D. Markham, and R. C. Gallo. 1986. Human T lymphotropic virus type III infection of human alveolar macrophages. Blood. 68:281-284.

7. Ho, D. D., T. R. Rota, and M. S. Hirsch. 1986. Infection of monocyte/macrophages by human T lymphotropic virus type III. $J$. Clin. Invest. 77:1712-1715.

8. Koyanagi, Y., S. Miles, R. T. Mitsuyasu, J. E. Merrill, H. V. Vinters, and I. S. Y. Chen. 1987. Dual infection of the central nervous system by AIDS viruses with distinct cellular tropisms. Science (Wash. DC). 236:819-822.

9. Crowe, S., J. Mills, and M. S. McGrath. 1987. Quantitative immunocytofluorographic analysis of CD4 surface antigen expression and HIV infection of human peripheral blood monocyte/macrophages. AIDS Research Human Retroviruses. 3:135-143.

10. Lane, H. C., and A. S. Fauci. 1985. Immunologic abnormalities in the acquired immunodeficiency syndrome. Annu. Rev. Immunol. 3:477-500.

11. Ho, D. D., R. J. Pomerantz, and J. C. Kaplan. 1987. Pathogenesis of infection with human immunodeficiency virus. $N$. Engl. J. Med. 317:278-286.
12. Berman, M. A., C. I. Sandborg, B. S. Calabia, B. S. Andrews, and G. J. Friou. 1987. Interleukin 1 inhibitor masks high interleukin 1 production in acquired immunodeficiency syndrome (AIDS). Clin. Immunol. Immunopathol. 42:133-140.

13. Scala, G., Y. D. Kuang, R. E. Hall, A. V. Muchmore, and J. J. Oppenheim. 1984. Accessory cell function of human B cells: I. Production of both interleukin 1-like activity and an interleukin 1 inhibitory factor by an EBV-transformed human B cell line. J. Exp. Med. 159:1637-1652.

14. Lifson, J. D., G. R. Reyes, M. S. McGrath, B. S. Stein, and E. G. Engleman. 1986. AIDS retrovirus induced cytopathology: giant cell formation and involvement of CD4 antigen. Science (Wash. DC). 232:1123-1127.

15. Colcher, D., and J. Scholom. 1980. Purification and characterization of RNA-directed DNA polymerase of a primate type-D retrovirus: Mason Pfizer virus. Biochim. Biophys. Acta. 607:445-456.

16. Higgins, J. R., N. C. Pederson, and J. R. Carlson. 1986. Detection and differentiation by sandwich enzyme-linked immunosorbent assay of human T-cell lymphotuopic virus type III/lymphadenopathyassociated virus- and acquired immunodeficiency syndrome-associated retrovirus-like clinical isolates. J. Clin. Microbiol. 24:424-430.

17. Locksley, R. M., F. P. Heinzel, J. M. Harlan, J. Agosti, T. E. Eessalu, B. B. Aggarwal, and H. M. Shepard. 1987. Tumor necrosis factors $\alpha$ and $\beta$ differ in their capacities to generate IL-1 release from human endothelial cells. J. Immunol. 139:1891-1895.

18. Gillis, S., M. Fern, W. Ou, and K. Smith. 1978. T-cell growth factor: parameters of production and a quantitative microassay for activity. J. Immunol. 120:2027-2032.

19. Watson, J. 1979. Continuous proliferation of murine antigen specific helper T lymphocytes in culture. J. Exp. Med. 150:1510-1521.

20. Cherwinski, H. M., J. H. Schumacher, K. D. Brown, and T. R. Mosmann. 1987. Two types of mouse helper T cell clone. III. Further differences in lymphokine synthesis between Th1 and Th2 clones revealed by RNA hybridization, functionally monospecific bioassays, and monoclonal antibodies. J. Exp. Med. 166:1229-1244.

21. Mosmann, T. R., H. Cherwinski, M. W. Bond, M. A. Giedlin, and R. L. Coffman. 1986. Two types of murine helper T cell clone. I. Definition according to profiles of lymphokine activities and secreted proteins. J. Immunol. 136:2348-2357.

22. Ohara, J., and W. E. Paul. 1985. Production of a monoclonal antibody to and molecular characterization of B-cell stimulatory factor-1. Nature (Lond.). 315:333-335.

23. Mosmann, T. R. 1983. Rapid colorimetric assay for cellular growth and survival: application to proliferation and cytotoxicity assays. J. Immunol. Methods. 65:55-66.

24. Dower, S. K., S. M. Call, S. Gillis, and D. L. Urdal. 1986. Similarity between the interleukin 1 receptors on a murine $\mathrm{T}$ lymphoma cell line and on a murine fibroblast cell line. Proc. Natl. Acad. Sci. USA. 83:1060-1064.

25. Chirgwin, J. M., A. E. Przybyla, R. J. MacDonald, and W. J. Rutter. 1979. Isolation of biologically active ribonucleic acid from sources enriched in ribonuclease. Biochemistry. 18:5294-5299.

26. Maniatis, T., E. F. Fitsch, and J. Sambrook. 1982. Molecular Cloning: A Laboratory Manual. Cold Spring Harbor Laboratory, Cold Spring Harbor, NY.

27. Meinkoth, J., and G. Wahl. 1984. Hybridization of nucleic acids immobilized on solid supports. Anal. Biochem. 138:267-284.

28. Auron, P. E., A. C. Webb, L. J. Rosenwasser, S. F. Mucci, A. Rich, S. M. Wolff, and C. A. Dinarello. 1984. Nucleotide sequence of human monocyte interleukin-1 precursor cDNA. Proc. Natl. Acad. Sci. USA. 81:7907-7911.

29. Fuhlbrigge, R. C., D. D. Chaplin, J. Kiely, and E. R. Unanue. 1987. Regulation of interleukin 1 gene expression by adherence and lipopolysaccharide. J. Immunol. 138:3799-3802.

30. Kleinerman, E. S., L. B. Lachman, R. D. Knowles, R. Snyderman, and G. J. Cianciolo. 1987. A synthetic peptide homologous to the envelope proteins of retroviruses inhibits monocyte-mediated killing by inactivating interleukin-1. J. Immunol. 139:2329-2337. 
31. Oppenheim, J. J., E. J. Kovacs, K. Matsushima, and S. K. Durum. 1986. There is more than one interleukin 1. Immunol. Today. 7:45-56.

32. Dinarello, C. A. 1984. Interleukin-1. Rev. Infect. Dis. 6:51-95.

33. Dinarello, C. A., L. J. Rosenwasser, and S. M. Wolff. 1981. Demonstration of a circulating suppressor factor of thymocyte proliferation during endotoxin fever in humans. J. Immunol. 127:25172519.

34. Liao, Z., R. S. Grimshaw, and D. L. Rosenstreich. 1984. Identification of a specific interleukin 1 inhibitor in the urine of febrile patients. J. Exp. Med. 159:126-136.

35. Arend, W. P., F. G. Joslin, and R. J. Massoni. 1985. Effects of immune complexes on production by human monocytes of interleukin 1 or an interleukin 1 inhibitor. J. Immunol. 134:3868-3875.

36. Roberts, Jr., N. J., A. H. Prill, and T. N. Mann. 1986. Interleukin 1 and interleukin 1 inhibitor production by human macrophages exposed to influenza virus or respiratory syncytial virus. Respiratory syncytial virus is a potent inducer of inhibitor activity. J. Exp. Med. 163:511-519.

37. Lotz, M., C. D. Tsoukas, C. A. Robinson, C. A. Dinarello, D. A. Carson, and J. H. Vaughan. 1986. Basis for defective responses of rheumatoid arthritis synovial fluid lymphocytes to anti-CD3 (T3) antibodies. J. Clin. Invest. 78:713-721.

38. Tiku, K., M. L. Tiku, S. Liu, and J. L. Skosey. 1986. Normal human neutrophils are a source of a specific interleukin 1 inhibitor. $J$. Immunol. 136:3686-3692.

39. Moissec, P., D. Cavender, and M. Ziff. 1986. Production of interleukin 1 by human endothelial cells. J. Immunol. 136:2486-2491.

40. Schwarz, T., A. Urbanska, F. Gschnait, and T. A. Luger. 1987. UV-irradiated epidermal cells produce a specific inhibitor of interleukin 1 activity. J. Immunol. 138:1457-1462.

41. Walsh, L. J., P. E. Lander, G. J. Seymour, and R. N. Powell. 1987. Isolation and purification of ILS, an interleukin 1 inhibitor produced by human gingival epithelial cells. Clin. Exp. Immunol. 68:366-374.

42. Fujiwara, H., and J. J. Ellner. 1986. Spontaneous production of a suppressor factor by the human macrophage-like cell line U937. $J$. Immunol. 136:181-185.

43. Lotz, M., C. D. Tsoukas, S. Fong, C. A. Dinarello, D. A. Carson, and J. H. Vaughan. 1986. Release of lymphokines after infection with Epstein Barr virus in vitro. II. A monocyte-dependent inhibitor of interleukin 1 downregulates the production of interleukin 2 and interferon- $\gamma$ in rheumatoid arthritis. J. Immunol. 136:3643-3648.

44. March, C. J., B. Mosley, A. Larsen, D. P. Cerretti, G. Braedt, V. Price, S. Gillis, C. S. Henney, S. R. Kronheim, K. Grabstein, P. J. Conlon, T. P. Hopp, and D. Cosman. 1985. Cloning, sequence and expression of two distinct human interleukin-1 complementary DNAs. Nature. 315:641-647.

45. Fenton, M. J., B. D. Clark, K. L. Collins, A. C. Webb, A. Rich, and P. E. Auron. 1987. Transcriptional regulation of the human prointerleukin $1 \beta$ gene. J. Immunol. 138:3972-3979.
46. Haq, A. U., J. J. Rinehart, and R. D. Maca. 1985. The effect of gamma interferon on IL-1 secretion of in vitro differentiated human macrophages. J. Leuk. Biol. 38:735-746.

47. Ranges, G. E., A. Zlotnik, T. Espevik, C. A. Dinarello, A. Cerami, and M. A. Pallidino, Jr. 1988. Tumor necrosis factor $\alpha /$ cachectin is a growth factor for thymocytes. Synergistic interactions with other cytokines. J. Exp. Med. 167:1472-1478.

48. Lotz, M., F. Jirik, P. Kabouridis, C. Tsoukas, T. Hirano, T. Kishimoto, and D. A. Carson. 1988. B cell stimulating factor 2 /interleukin 6 is a costimulant for human thymocytes and T lymphocytes. $J$. Exp. Med. 167:1253-1258.

49. Kurt-Jones, E. A., S. Hamberg, J. Ohara, W. E. Paul, and A. K. Abbas. 1987. Heterogeneity of helper/inducer T lymphocytes. I. Lymphokine production and lymphokine responsiveness. J. Exp. Med. 166:1774-1787

50. Muchmore, A. V., and J. M. Decker. 1987. Evidence that recombinant IL $1 \alpha$ exhibits lectin-like specificity and binds to homogeneous uromodulin via $\mathrm{N}$-linked oligosaccharides. J. Immunol. 138:2541-2546.

51. Pennica, D., W. J. Kohr, W. Kuang, D. Glaister, B. B. Aggarwal, E. Y. Chen, and D. V. Goeddel. 1987. Identification of human uromodulin as the Tamm-Horsfall urinary glycoprotein. Science (Wash. DC). 236:83-88.

52. Sporn, M. B., A. B. Roberts, L. M. Wakefield, and R. K. Assoian. 1986. Transforming growth factor- $\beta$ : Biological function and chemical structure. Science (Wash. DC). 233:532-534.

53. Sechinger, P., J. W. Lowenthal, K. Williamson, J. M. Dayer, and H. R. MacDonald. 1987. A urine inhibitor of interleukin 1 activity that blocks ligand binding. J. Immunol. 139:1546-1549.

54. Brown, K. M., and D. L. Rosenstreich. 1987. Mechanism of action of a human interleukin 1 inhibitor. Cell. Immunol. 105:45-53.

55. Murray, H. W., J. K. Hillman, B. Y. Rubin, C. D. Kelly, J. L. Jacobs, L. W. Tyler, D. M. Donelly, S. M. Carriero, J. H. Godbold, and R. B. Roberts. 1985. Patients at risk for AIDS-related opportunistic infections. Clinical manifestations and impaired gamma interferon production. N. Engl. J. Med. 313:1504-1510.

56. Heagy, W., V. E. Kelley, T. B. Strom, K. Mayer, H. M. Shapiro, R. Mandel, and R. Sinberg. 1984. Decreased expression of human class-II antigens on monocytes from patients with acquired immune deficiency syndrome. Increased expression with interferon- $\gamma$. J. Clin. Invest. 74:2089-2096.

57. Belsito, D. V., M. R. Sanchez, R. L. Baer, F. Valentine, and G. J. Thorbecke. 1984. Reduced Langerhans' cell Ia antigen and ATPase activity in patients with the acquired immunodeficiency syndrome. N. Engl. J. Med. 310:1279-1282.

58. Petit, A. J. C., F. G. Terpstra, and F. Miedema. 1987. Human immunodeficiency virus infection down-regulates HLA class II expression and induces differentiation in promonocytic U937 cells. $J$. Clin. Invest. 79:1883-1889. 